\title{
Echocardiographic findings of large patent ductus arteriosus in the very low birthweight infant before and after treatment with indomethacin
}

\author{
H. L. HALLIDAY, T. HIRATA, AND J. P. BRADY \\ Children's Hospital of San Francisco, and Cardiovascular Research Institute, University of California, USA
}

SUMMARY 17 very low birthweight infants (mean birthweight $850 \mathrm{~g}$ ) with large patent ductus arteriosus (PDA) were studied by echocardiography before and after treatment with indomethacin. Before treatment left heart dimensions were increased suggesting large left-to-right shunt. Echographic measurements of augmented left ventricular (LV) contraction could be attributed to increase in preload, and reduction in afterload in PDA. After indomethacin, in infants showing clinical response, left heart dimensions returned rapidly to normal and LV contraction became normal or reduced. Two infants had reduced LV contraction with persistent pulmonary oedema suggesting LV failure. In contrast, infants showing no clinical response to the drug also had no significant changes in echographic measurements. Right ventricular systolic time intervals (RPEP/RVET) did not alter after indomethacin treatment in either group, suggesting that the drug does not increase pulmonary vascular resistance.

Echocardiographic assessment of left-to-right ductus shunt by measuring the left heart dimensions has been a major advance in the management of infants with patent ductus arteriosus (PDA). From left atrial to aorta ratio (LA/Ao) (Silverman et al., 1974), left atrial dimension (LAD), and left ventricular end-diastolic dimension (LVEDD) (Baylen et al., $1975)$ the size of shunt can be estimated. The echocardiogram can also be used to assess left ventricular performance (Sahn et al., 1974) and pulmonary vascular resistance in the newborn (Hirschfeld et al., 1975a; Riggs et al., 1977). Measurements of left ventricular function in infants with PDA before and after ductus ligation have already been reported (Baylen et al., 1977), but no data are available on the effects of indomethacin on left ventricular function and pulmonary vascular resistance in infants with large PDA. The purpose of this paper is to present our echocardiographic findings in 17 very low birthweight infants with large PDA who were given indomethacin.

\footnotetext{
Royal Maternity Hospital, Belfast

H. L. HALLIDAY, locum neonatologist

Children's Hospital of San Francisco, California

T. HIRATA, neonatologist

J. P. BRADY, neonatologist
}

\section{Patients and methods}

17 infants of mean gestational age $27 \cdot 2$ weeks and mean birthweight $850 \mathrm{~g}$ were given indomethacin in a total dose of 0.2 to $0.6 \mathrm{mg} / \mathrm{kg}$ for large PDA. The diagnosis of PDA and the method of administration of the drug have been described elsewhere (Halliday et al., 1979). The mean total dose of indomethacin was $0.38 \mathrm{mg} / \mathrm{kg}$ and the median age at treatment was 6 days (range 4-66). Four infants had severe respiratory distress (requiring $\mathrm{F}_{1} \mathrm{O}_{2}>0 \cdot 60$ and assisted ventilation after 24 hours of age). 15 infants were treated with mechanical ventilation, one with mask CPAP, and one did not require ventilatory support when the drug was given. Six infants had been treated with digoxin and 5 with frusemide before being given indomethacin. There were 13 girls and 4 boys.

Echocardiograms were recorded using an Ekoline 20 ultrasonoscope (Smith-Kline Instruments) with a $5 \mathrm{MHz}$ focused transducer. Studies were performed serially before giving indomethacin and within 3 days afterwards (mean 1.3). LAD and LVEDD were measured using methods previously described (Feigenbaum, 1972). LA/Ao was measured using the method of Silverman et al. (1974) (coefficient of 
variation $\pm 7 \cdot 0 \%$ ). Percentage shortening of the internal diameter (SID) of the left ventricle was calculated from the formula (Baylen et al., 1977):

$$
\% \text { SID }=(\text { LVEDD-LVESD }) / \text { LVEDD } \times 100
$$

where LVESD = left ventricular end systolic dimension (Fig. 1). The systolic time intervals of both ventricles, the pre-ejection period (PEP), and ventricular ejection time (VET) were measured as previously described (Hirschfeld et al., 1975b; Halliday et al., 1977) (Fig. 2). Many of these tiny infants were being mechanically ventilated at the time of study and this may alter these measurements. For this reason at least 10 consecutive ventricular systoles were examined to give the mean systolic time intervals (coefficient of variation $\pm 4.8 \%$ ).

Values before and after indomethacin were compared by the paired Student's $t$ test.

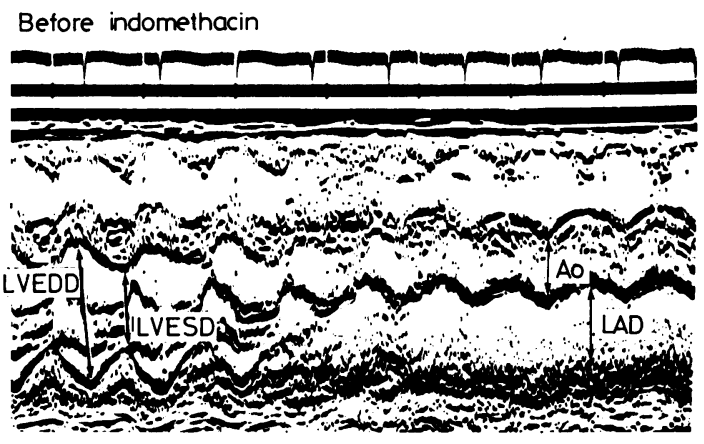

After indomethacin

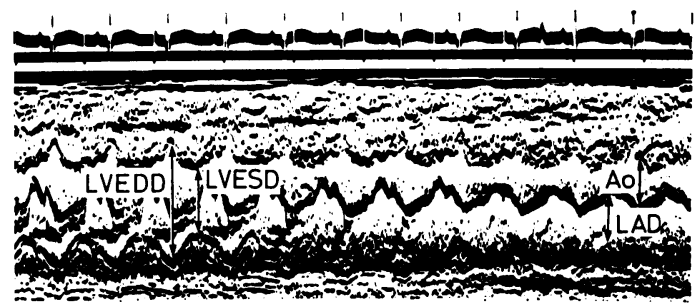

Fig. 1 Echocardiograms of left ventricle with sweep to aorta and left atrium before and after indomethacin treatment for large PDA in a 750-g infant. The echocardiograms are not recorded on the same scale. Fig. la (before indomethacin) shows left ventricular end-distolic dimension $(L V E D D)=1.7 \mathrm{~cm}$, left ventricular end-systolic dimension (LVESD) $=0.9 \mathrm{~cm}$, percentage shortening of internal dimension of $L V$ $(\% S I D)=47 \%$, left atrial dimension $(L A D)=0.9 \mathrm{~cm}$, and left atrial to aorta ratio $(L A \mid A o)=1 \cdot 6: 1$.

After indomethacin (Fig. 1b) the measurements become $L V E D D=1.35 \mathrm{~cm}, L V E S D=0.8 \mathrm{~cm}, \% S I D=41 \%$, $L A D=0.7 \mathrm{~cm}$, and $L A \mid A O=1 \cdot 2: 1$.

$$
\begin{gathered}
\text { Before } \\
\frac{\text { LPEP }}{\text { LVET }}=\frac{38}{194}=0.20
\end{gathered}
$$

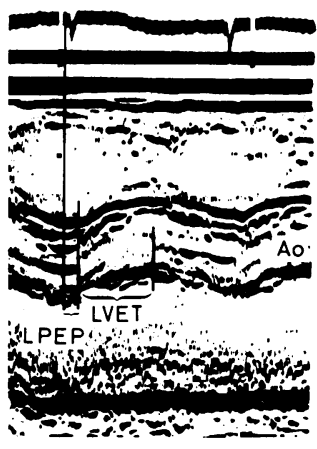

Fig. 2 Echocardiograms of aortic valve at paper speeds of $100 \mathrm{~mm} / \mathrm{s}$ before and after treatment with indomethacin in a 750-g infant. Before treatment left ventricular pre-ejection period $(L P E P)=38 \mathrm{~ms}$, left ventricular ejection time $(L V E T)=194 \mathrm{~ms}$, and LPEP/LVET $=$ $0 \cdot 20$. After treatment LPEP $=64 \mathrm{~ms}, L V E T=178 \mathrm{~ms}$, and $L P E P / L V E T=0 \cdot 36$.

\section{Results}

After treatment with indomethacin, 13 of 17 infants showed good clinical response with reduced intensity of the murmur, decreased pulses and praecordial activity, and less need for ventilatory support (group 1). Within 3 days the PDA had closed in these infants. The remaining 4 infants showed little or no clinical response to indomethacin (group 2). These two groups of infants were of similar gestational ages, birthweights, sexes, and age at treatment. Incidence of severe respiratory distress, and pretreatment with digoxin or frusemide was also similar (Table 1).

Echocardiographic findings before treatment were similar in both groups (Table 2).

Table 1 Comparison of clinical characteristics of infants with and without clinical response to indomethacin (mean $\pm 1 S D)$

\begin{tabular}{llll}
\hline & $\begin{array}{l}\text { Group 1 }(n=13) \\
\text { Responders }\end{array}$ & $\begin{array}{l}\text { Group 2 }(n=4) \\
\text { Nonresponders }\end{array}$ & $P$ \\
\hline Gestational age (weeks) & $27 \cdot 3 \pm 1 \cdot 3$ & $27.0 \pm 1.6$ & NS \\
Birthweight (g) & $845 \pm 180$ & $875 \pm 195$ & NS \\
Sex (male/female) & $4 / 9$ & $0 / 4$ & NS \\
Severe respiratory distress & $3(23 \%)$ & $1(25 \%)$ & NS \\
$\begin{array}{l}\text { Prior digoxin therapy } \\
\text { Median age at treatment }\end{array}$ & $4(36 \%)$ & $1(25 \%)$ & NS \\
$\begin{array}{l}\text { (days) } \\
\text { Total dose of indomethacin } \\
\text { (mg/kg) }\end{array}$ & $\mathbf{6}(4-66)$ & $7(4-39)$ & NS \\
\hline
\end{tabular}


Table 2 Comparison of echocardiographic and blood pressure findings before and after treatment with indomethacin in groups 1 and 2

\begin{tabular}{|c|c|c|c|c|c|c|}
\hline & \multicolumn{3}{|c|}{ Group 1 (responders) $(n=13)$} & \multicolumn{3}{|c|}{ Group 2 (nonresponders) $(n=4)$} \\
\hline & Before & After & $P$ & Before & After & $P$ \\
\hline $\begin{array}{l}\text { HR (beats/min) } \\
\text { LAD (cm) } \\
\text { LA/Ao } \\
\text { LVEDD (cm) } \\
\% \text { SID (\%) } \\
\text { LPEP (ms) } \\
\text { LVET (ms) } \\
\text { LPEP/LVET } \\
\text { RPEP/RVET } \\
\text { SBP (mmHg) } \\
\text { DBP (mmHg) }\end{array}$ & $\begin{array}{l}149 \\
1.05 \\
1.69 \\
1 \cdot 45 \\
40 \cdot 4 \\
42 \\
181 \\
0 \cdot 23 \\
0 \cdot 33 \\
51 \\
24\end{array}$ & $\begin{array}{l}142 \\
0 \cdot 72 \\
1 \cdot 16 \\
1 \cdot 21 \\
34 \cdot 8 \\
56 \\
165 \\
0 \cdot 35 \\
0 \cdot 31 \\
62 \\
30\end{array}$ & $\begin{array}{l}\text { NS } \\
<0.001 \\
<0.001 \\
<0.01 \\
<0.01 \\
<0.001 \\
<0.02 \\
<0.001 \\
\text { NS } \\
<0.01 \\
<0.01\end{array}$ & $\begin{array}{l}149 \\
0 \cdot 90 \\
1 \cdot 49 \\
1 \cdot 15 \\
40 \cdot 5 \\
45 \\
176 \\
0 \cdot 25 \\
0 \cdot 35 \\
52 \\
27\end{array}$ & $\begin{array}{l}148 \\
0 \cdot 90 \\
1 \cdot 43 \\
1 \cdot 08 \\
39 \cdot 5 \\
47 \\
174 \\
0 \cdot 27 \\
0 \cdot 31 \\
51 \\
29\end{array}$ & $\begin{array}{l}\text { NS } \\
\text { NS } \\
\text { NS } \\
\text { NS } \\
\text { NS } \\
\text { NS } \\
\text { NS } \\
\text { NS } \\
\text { NS } \\
\text { NS } \\
\text { NS }\end{array}$ \\
\hline
\end{tabular}

HR = Heart rate; LAD = left atrial dimension; LA/Ao = left atrial to aorta ratio; LVEDD = left ventricular end diastolic dimension; $\%$ SID = percentage shortening of the internal dimension of LV; LPEP = left ventricular pre-ejection period; LVET = LV ejection time; RPEP = right ventricular pre-ejection period; $R$ VET $=\mathrm{RV}$ ejection time; $\mathbf{S B P}=$ systolic blood pressure; $\mathrm{DBP}=$ diastolic blood pressure.

Left heart dimensions (LAD, LA/Ao, and LVEDD). These echographic measurements of left heart size were increased before treatment in both groups when compared with normal values of Baylen et al. $(1975,1977)$ and Silverman et al. (1974) (Figs 1 and 3). Our normal LA/Ao values are somewhat higher than those of Silverman et al. (1974) $1 \cdot 1 \pm 0 \cdot 1$ (H. L. Halliday and J. Keroes, 1977, unpublished observations). The measurements in responding

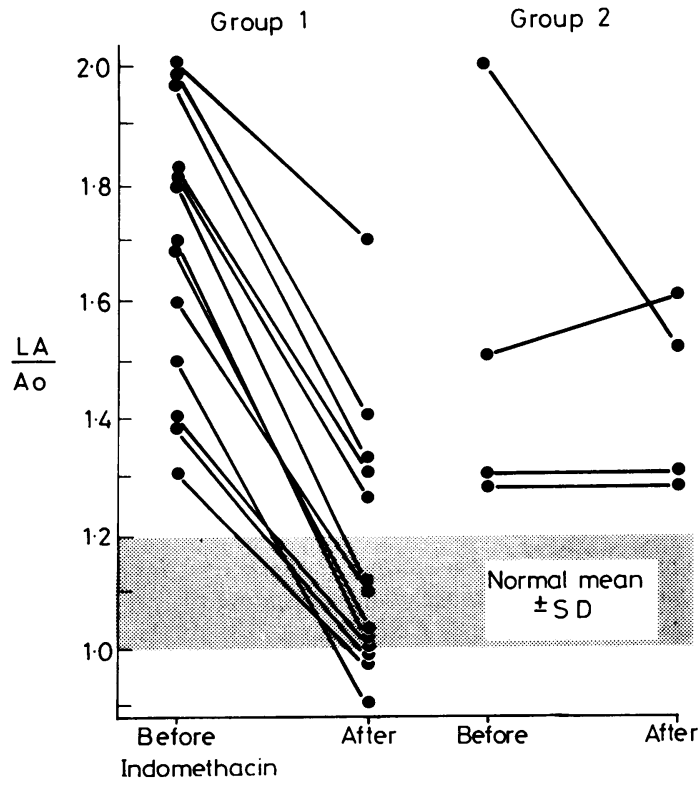

Fig. 3 Comparison of changes in LA/Ao ratio after treatment with indomethacin in groups 1 and 2.

Shaded area represents normal mean $\pm 1 S D$

(H. L. Halliday and J. Keroes, 1977, unpublished observations). infants (group 1) tended to be higher than those in nonresponding ones (group 2) (Table 2) but the differences were not statistically significant. After indomethacin treatment, group 1 infants showed decrease in left heart dimensions to the normal range (Fig. 1b), often within 24 hours and, in 2 infants, by 4 hours after administration. Fig. 4 shows measurements from a typical infant.

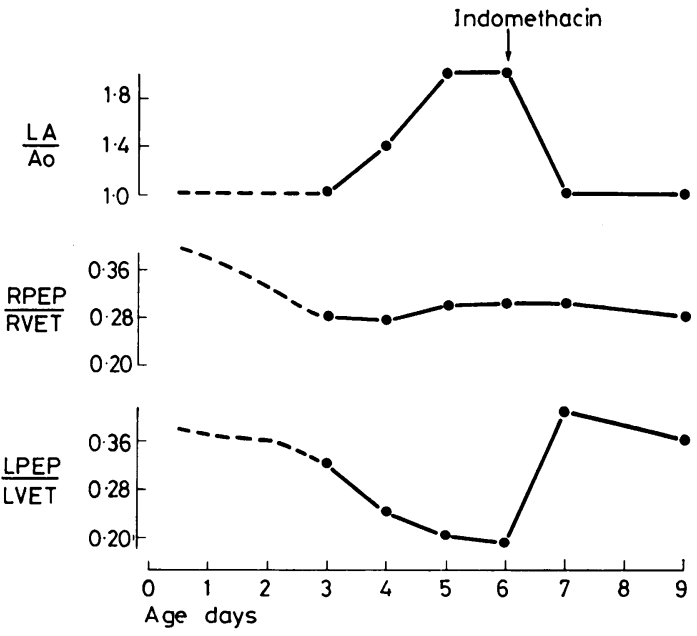

Fig. 4 Measurement from serial echocardiograms of a 750-g infant who developed a large PDA. Dashed lines show previously reported results (Silverman et al., 1974; Halliday et al., 1978). As clinical evidence of PDA appears about the fourth day of life, $L A /$ Ao ratio increases and LPEP/LVET ratio decreases while $R P E P / R V E T$ ratio is unchanged. Indomethacin was given on day 6 and $L A \mid A o$ and $L P E P / L V E T$ rapidly returned to normal while RPEP/RVET did not change. 
Percentage shortening of internal dimension of $\mathrm{LV}$ ( $\%$ SID). Levels before treatment were about $40 \%$ (normal $=33 \cdot 5 \%$ ). After treatment group 1 infants had a decrease in $\%$ SID to $34.8 \%(P<0.01)$, but group 2 infants showed no such change (Table 2 and Fig. 5).

Systolic time intervals. In both groups mean LPEP/ LVET was less than $0 \cdot 26$ (Figs 2 and 6) and normal for preterm infants without PDA is 0.32 (Halliday et al., 1978). The ratio was decreased as a result of reduced LPEP and increased LVET (Table 2). After treatment values returned to normal in group 1 (Figs 2 and 6). Mean RPEP/RVET ratios were normal in both groups and were unaffected by indomethacin.

Blood pressure and heart rate (Table 2). Heart rate did not alter in either group but blood pressure in responding infants increased significantly from mean $51 / 24$ to $62 / 30 \mathrm{mmHg}$.

Correlations. LPEP/LVET was negatively correlated with LA/Ao by the following formula: LPEP/ LVET $=-0.14($ LA/Ao $)+0.48(\mathrm{r}=-0.67)$ and positively with diastolic blood pressure-LPEP/ $\mathrm{LVET}=0.004(\mathrm{DBP})+0 \cdot 17(\mathrm{r}=0 \cdot 45)$.

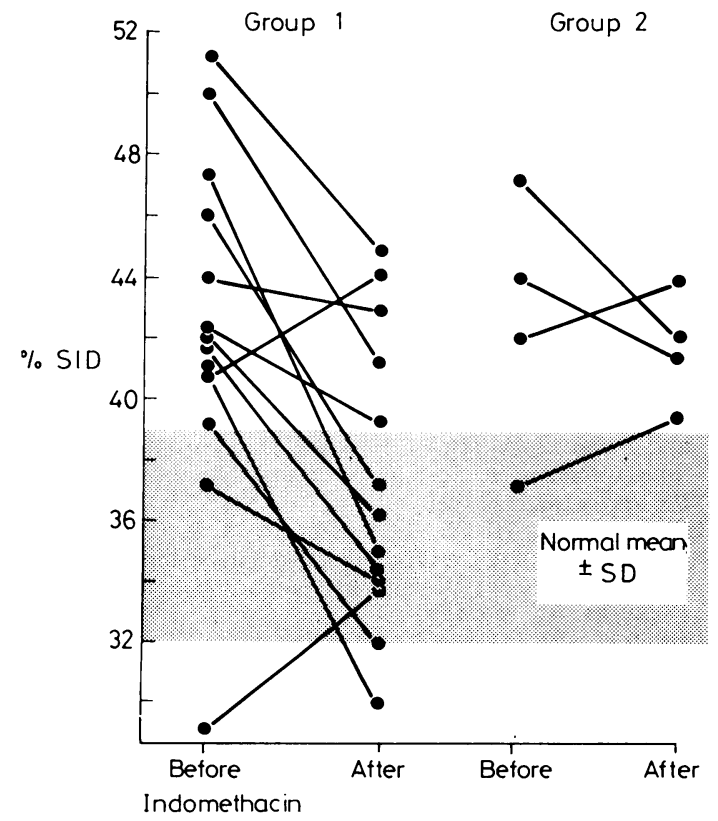

Fig. 5 Comparison of \% SID changes before and after treatment with indomethacin in groups 1 and 2. Shaded area represents normal mean $\pm 1 S D$ (Baylen et al., 1975, 1977).

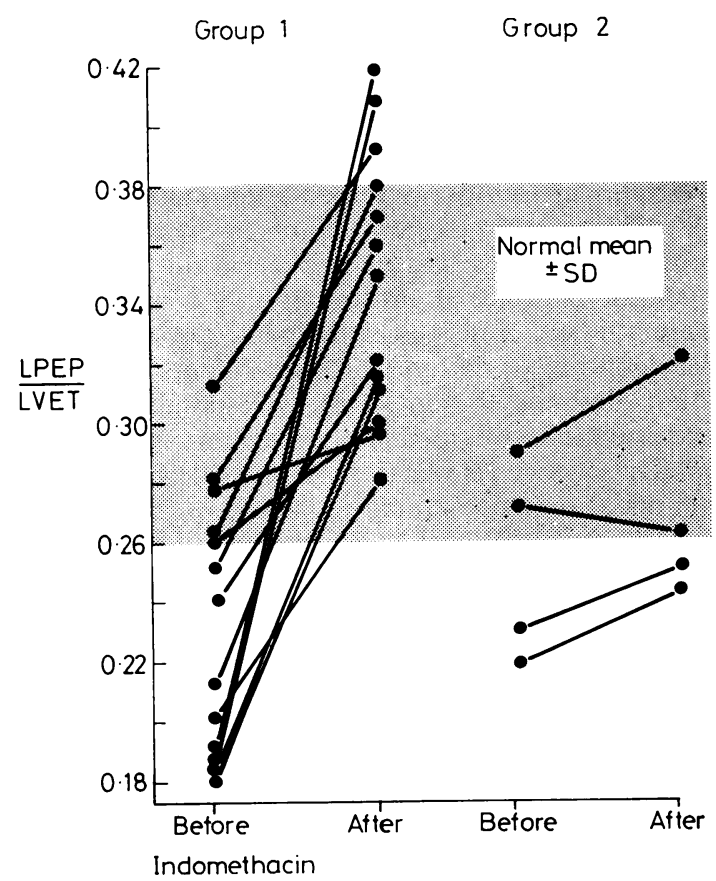

Fig. 6 Comparison of changes in echocardiographic ratio LPEP/LVET in groups 1 and 2 after indomethacin treatment. Shaded area represents normal mean $\pm 1 S D$ (Halliday et al., 1978). Note the 2 infants in group 1 in whom LPEP/LVET was over 0.40 after treatment.

\section{Discussion}

In the infant with large PDA, torrential left-to-right shunt will result in left ventricular and left atrial dilatation (Silverman et al., 1974; Baylen et al., 1975). Left atrial and left ventricular end-diastolic dimensions, and left atrial to aorta ratio have been shown to increase in left-to-right shunts including large PDA. After ductus ligation these dimensions rapidly revert to normal (Silverman et al., 1974; Baylen et al., 1975). There have been relatively few echocardiographic studies of left ventricular function in large PDA (Kaye et al., 1975; Sahn et al., 1976; Baylen et al., 1977). Because of the reduced afterload, shortening of left ventricle (\% SID) will increase and may spuriously suggest improved left ventricular contractility in PDA (Quinones et al., 1975). Similarly, the ratio LPEP/LVET, which has been used as a measure of LV contractility (Weissler et al., 1969; Halliday et al., 1977), will be influenced by reduction in afterload in PDA.

Our infants with large PDA had increased left 
heart dimensions and presumably raised LV preload. In addition, increased \% SID, and decreased LPEP/LVET could be reflections of the decreased afterload. After indomethacin administration left heart dimensions decreased rapidly and the changes were similar to those observed after ductus ligation. In indomethacin-treated infants whose murmurs remained, no significant reduction in left heart dimensions occurred. Although only 4 such infants were studied, 3 needed subsequent ductus ligation for continued failure. These infants probably attained similar blood levels as responding infants because they developed reduced urinary excretion of similar severity (Halliday et al., 1979). Responding infants also demonstrated reduction in \% SID, and increase in LPEP/LVET. We attribute these changes to increase in LV afterload and decrease in preload to normal levels after closure of the ductus. This is consistent with the relationship found between LPEP/LVET and diastolic blood pressure (afterload) and LA/Ao ratio (preload). It is possible however, that indomethacin had a direct myocardial depressive effect. The drug has been shown to raise coronary vascular resistance in the isolated animal heart without changing performance (Schror et al., 1976), and a recent report of infant death from myocardial infarction and pneumonia after treatment with indomethacin has been published (Merritt et al., 1978). Nevertheless, we feel that the signs of decreased LV contractility after indomethacin were due to the effect of ductus closure rather than to myocardial depression as they did not occur in infants whose ductus remained open. Furthermore the changes were similar to those after ductus ligation (Park et al., 1973; Baylen et al., 1975).

In 2 infants the echographic signs of decreased LV contractility were exaggerated with \% SID below 32 and LPEP/LVET over 0.40 after treatment. These infants had persistent signs of pulmonary oedema, despite clinical closure of the ductus. This finding is in keeping with previous reports of depressed LV function after ductus ligation (Park et al., 1973; Baylen et al., 1975). We feel that LV failure resulted from rapid ductus closure with sudden increase in afterload to normal levels which stressed the already dilated and compromised LV.

Right ventricular systolic time intervals (RPEP/ RVET) have been shown to correlate with pulmonary vascular resistance in infants and children (Hirschfeld et al., 1975a). Despite a recent study showing increased pulmonary vascular resistance after administration of indomethacin to premature goats (Tyler et al., 1975) we found no echocardiographic evidence to support this finding in our very low birthweight infants.

In summary, very low birthweight infants with large PDA have echocardiographic evidence of increased left heart dimensions and augmented LV contraction as a result of increased preload and reduced afterload. After ductus closure with indomethacin left heart dimensions rapidly return to normal (in 2 infants within 4 hours of treatment). There was no evidence of increased pulmonary vascular resistance after treatment but 2 infants showed signs of decreased LV contractility and had persistent pulmonary oedema possibly due to LV failure. This we attribute to the effects of rapid ductus closure with sudden increase in afterload rather than to direct myocardial depression by indomethacin.

We thank Dr A. M. Rudolph, Dr J. Keroes, and Dr H. C. Mulholland for help and advice in preparation of this manuscript, and Miss Denise McAfee for typing it.

This study was supported in part by Pulmonary Scor HL 19185 from the United States Public Health Service.

\section{References}

Baylen, B. G., Meyer, R. A., Kaplan, S., Ringenburg, W. T., and Korfhagen, J. (1975). The critically ill premature infant with patent ductus arteriosus and pulmonary disease-an echocardiographic assessment. Journal of Pediatrics, 86, 423-432.

Baylen, B. G., Meyer, R. A., Korfhagen, J., Benzing, G., III, Bubb, M. E., and Kaplan, S. (1977). Left ventricular performance in the critically ill premature infant with patent ductus arteriosus and pulmonary disease. Circulation, 55, 182-188.

Feigenbaum, H. (1972). Echocardiography. Lea and Febiger: Philadelphia.

Halliday, H. L., Hirschfeld, S. S., Riggs, T., Liebman, J., Fanaroff, A., and Bormuth, C. (1977). Respiratory distress syndrome: echocardiographic assessment of cardiovascular function and pulmonary vascular resistance. Pediatrics, 60, 444-449.

Halliday, H. L., Hirschfeld, S. S., Riggs, T., Liebman, J., and Fanaroff, A. (1978). Echographic ventricular systolic time intervals in normal term and preterm neonates. Pediatrics, 62, 317-321.

Halliday, H. L., Hirata, T., and Brady, J. P. (1979). Indomethacin therapy for large patent ductus arteriosus in the very low birth weight infant: results and complications. Pediatrics, 64, 154-159.

Hirschfeld, S. S., Meyer, R. A., Schwartz, D. C., Korfhagen, J., and Kaplan, S. (1975a). The echocardiographic assessment of pulmonary artery pressure and pulmonary vascular resistance. Circulation, 52, 642-650.

Hirschfeld, S. S., Meyer, R. A., Schwartz, D. C., Korfhagen, J., and Kaplan, S. (1975b). Measurement of right and left ventricular systolic time intervals by echocardiography. Circulation, 51, 304-309.

Kaye, H. H., Tynan, M., and Hunter, S. (1975). Validity of echocardiographic estimates of left ventricular size and performance in infants and children. British Heart Journal, 37, 371-375. 
Merritt, T. A., Gluck, L., Higgins, C., Friedman, W. F., and Nyhan, W. L. (1978). Management of premature infants with patent ductus arteriosus. Specialty conference. Western Journal of Medicine, 128, 212-222.

Park, S. C., Steinfeld, L., and Dimich, I. (1973). Systolic time intervals in infants with congestive heart failure. Circulation, 47, 1281-1288.

Quinones, M. A., Gaasch, W. H., Cole, J. S., and Alexander, J. R. (1975). Echocardiographic determination of left ventricular stress-velocity relations in man: with reference to the effects of loading and contractility. Circulation, 51, 689-712.

Riggs, T., Hirschfeld, S. S., Bormuth, C., Fanaroff, A., and Liebman, J. (1977). Neonatal circulatory changes: an echocardiographic study. Pediatrics, 59, 338-344.

Sahn, D. J., Deely, W. J., Hagan, A. D., and Friedman, W. F. (1974). Echocardiographic assessment of left ventricular performance in normal newborns. Circulation, 49, 232-236.

Sahn, D. J., Vaucher, Y., Williams, D. E., Allen, H. D., Goldberg, S. J., and Friedman, W. F. (1976). Echocardiographic detection of large left to right shunts and cardiomyopathies in infants and children. American Journal of Cardiology, 38, 73-79.

Schror, K., Krebs, R., and Nookhwunc, C. (1976). Increase in the coronary vascular resistance by indomethacin in the isolated guinea pig heart preparation in the absence of changes in mechanical performance and oxygen consumption. European Journal of Pharmacology, 39, 161-169.

Silverman, N. H., Lewis, A. B., Heymann, M. A., and Rudolph, A. M. (1974). Echocardiographic assessment of ductus arteriosus shunt in premature infants. Circulation, 50, 821-825.

Tyler, T., Wallis, C., Leffler, C., and Cassin, S. (1975). The effects of indomethacin on pulmonary vascular response to hypoxia in the premature and mature newborn goat. Proceedings of the Society for Experimental Biology and Medicine, 150, 695-698.

Weissler, A. M., Harris, W. S., and Schoenfeld, C. D. (1969). Bedside technics for the evaluation of left ventricular function in man. American Journal of Cardiology, 23, 577-583.

Correspondence to Dr H. L. Halliday, Department of Child Health, Institute of Clinical Science, Grosvenor Road, Belfast BT12 6BJ, Northern Ireland.

Received 12 December 1978 